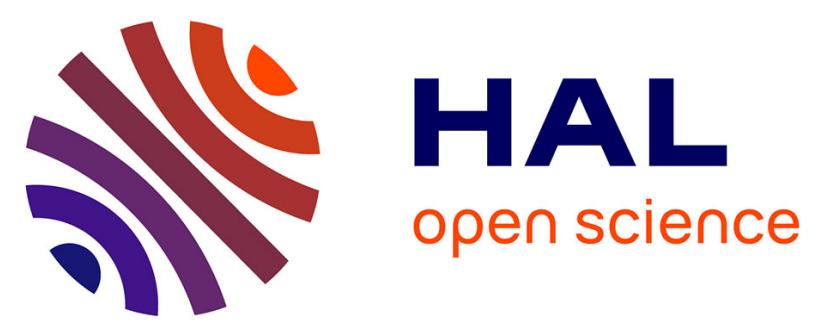

\title{
Muc5b is mainly expressed and sialylated in the nasal olfactory epithelium whereas Muc5ac is exclusively expressed and fucosylated in the nasal respiratory epithelium.
}

Salah-Eddine Amini, Valérie Gouyer, Céline Portal, Frederic Gottrand, Jean-Luc Desseyn

\section{To cite this version:}

Salah-Eddine Amini, Valérie Gouyer, Céline Portal, Frederic Gottrand, Jean-Luc Desseyn. Muc5b is mainly expressed and sialylated in the nasal olfactory epithelium whereas Muc5ac is exclusively expressed and fucosylated in the nasal respiratory epithelium.. Histochemistry and Cell Biology, 2019, Histochemistry and cell biology, 152, pp.167-174. 10.1007/s00418-019-01785-5 . hal-02281443v2

\author{
HAL Id: hal-02281443 \\ https://hal.univ-lille.fr/hal-02281443v2
}

Submitted on 18 Nov 2019

HAL is a multi-disciplinary open access archive for the deposit and dissemination of scientific research documents, whether they are published or not. The documents may come from teaching and research institutions in France or abroad, or from public or private research centers.
L'archive ouverte pluridisciplinaire HAL, est destinée au dépôt et à la diffusion de documents scientifiques de niveau recherche, publiés ou non, émanant des établissements d'enseignement et de recherche français ou étrangers, des laboratoires publics ou privés. 


\section{Muc5b is mainly expressed and sialylated in the nasal olfactory epithelium whereas Muc5ac is exclusively expressed and fucosylated in the nasal respiratory epithelium}

Salah-Eddine Amini ${ }^{1 \#}$, Valérie Gouyer ${ }^{1 \#}$, Céline Portal ${ }^{1,2}$, Frédéric Gottrand ${ }^{1}$, Jean-Luc Desseyn $^{1 *}$

1- Univ. Lille, Inserm, CHU Lille, LIRIC UMR 995, F-59000 Lille, France

2- Johns Hopkins University, School of Medicine, Wilmer Eye Institute, Baltimore, MD 21201

\#-Contributed equally

\section{*Corresponding author}

Jean-Luc Desseyn, PhD

Inserm, Univ. de Lille, CHU Lille, LIRIC UMR 995

Faculté de Médecine, Pôle Recherche, $5^{\text {ème }}$ étage, 1 place de Verdun, F-59000 Lille, France

Tel: (+33) 320627789

e-mail: jean-luc.desseyn@inserm.fr

ORCID: 0000-0001-6876-8049

\section{Competing interests}

The authors declare that they have no competing interests.

\section{Fundings}

S.-E. A. is the recipient of a «Université de Lille» fellowship. C.P. is the recipient of a "Université Lille 2" fellowship. 


\section{Abstract}

The nose is a complex organ that filters and warms breathing airflow. The nasal epithelium is the first barrier between the host and the external environment and is covered by a mucus gel that is poorly documented. Mucins are large, heavily $O$-glycosylated polymeric molecules secreted in the nose lumen by specialized cells, and they are responsible for the biochemical properties of the mucus gel. The mucus traps particles and clears them, and it also bathes microbiota, host molecules, and receptors that are all essential for odor perception in the olfactory epithelium. We used histology and immunohistochemistry to study the expression of the two main airway polymeric mucins, Muc5ac and Muc5b, in wild-type, green fluorescent protein-reporter Muc5b, and in genetically Muc5b-deficient mice. We report that Muc5ac is produced by goblet cells at the cell surface in the respiratory epithelium but is not expressed in the olfactory epithelium, whereas Muc $5 \mathrm{~b}$ is secreted by Bowman's glands situated in the lamina propria beneath the olfactory epithelium and also by goblet cells in the distal part of the respiratory epithelium. We also observed that Muc5b-deficient mice exhibited depletion of Bowman's glands. Using lectins, we found that terminally $O$-glycosylated chains of Muc5b were sialylated but not fucosylated, whereas Muc5ac was fucosylated but not sialylated. Specific localization and specific terminal glycosylation of the two mucins suggest different functions of the mucins.

Keywords Mouse nose $\cdot$ Mucin $\cdot$ Muc5b · Muc5ac $\cdot$ Lectin · Bowman's gland 


\section{Introduction}

The nose is a complex and well-structured organ, and it is the respiratory entrance hall in all mammalian species. The nasal cavity of both humans and mice is divided into compartments that are grossly organized in turbinates from the nostril to the nasopharynx. These bony structures increase the inner nasal surface area. Among the four nasal epithelial populations, the respiratory epithelium (RE) and the olfactory epithelium (OE) are the two main epithelia covering more than $90 \%$ of the total surface epithelium. Most of the luminal surfaces of the nasal compartments are covered by a continuous gel-like mucus layer that retains a high quantity of water that humidifies the breathing air before it reaches the lungs. The mucus layer also traps and clears bacteria, viruses and particles that are moved distally by cilia toward the naso- and oropharynx, where they are swallowed by the esophagus to clear the nasal cavity (Harkema et al. 2006). The proximal half of the mouse nasal cavity is covered by RE that is much larger in humans compared with rodents. The distal half of the nasal cavity is lined by OE that covers approximately $46 \%$ of the nasal cavity in mice vs $3 \%$ in humans reflecting a loss of the olfactory system in comparison to other mammals (Gross et al. 1982).

Gel-forming mucins (GFMs) are secreted polymeric macromolecules that constitute the framework of all mammalian mucus hydrogels and are responsible for the gel properties. However, other molecules such as cell-surface mucins are important components of the mucus gel. Their extracellular region can be seen as components of the mucus and may contribute to its viscoelastic properties, following shedding or direct secretion via splicing, and may bind GFMs (Linden et al. 2008; Radicioni et al. 2016). Mucins are highly $O$-glycosylated molecules. The numerous glycan chains are linked to Ser and Thr amino acids clustered in the central region of the mucin backbone. Three regions can be identified in $O$-glycan chains: the core, the backbone, and the periphery (Corfield 2017). Among the numerous terminal glycotopes, fucosylated (Fucose- $\alpha-(1,2)-$ Galactose) and sialylated (Neu5Ac- $\alpha-(2,3)$ and $\alpha-(2,6)$-Galactose) glycotopes are very common. It is believed 
that the different glycotopes in cells of the same tissue reflect specific functions (Corfield 2017). GFMs are encoded by five genes conserved between humans and rodents. Human MUC5B and MUC5AC (murine Muc5b and Muc5ac) are the two predominant human GFMs in the airways. The RE contains a high concentration of goblet cells, and the human RE also comprises subepithelial tubuloacinar glands (Ali and Pearson 2007). It has been reported using in situ hybridization that human MUC5AC is the major GFM, which is mainly expressed by goblet cells, whereas $M U C 5 B$ is expressed by the submucosal glands in the inferior turbinates (Aust et al. 1997). Mucins from other sites may also participate into the mucus gel of the nose. Indeed, the nasolacrimal ducts that produced the GFM MUC5B, the secreted non-GFM MUC7 as well as the two other GFMs MUC5AC and MUC2 drain into the nasal cavity the tear fluid (for review see (Paulsen 2006)). Bowman's glands (BGs) are branched, tubular-type, submucosal glands composed of acini (Chen et al. 2014). Through narrow ducts, they secrete neutral and acidic glycoconjugates including one or more GFMs that form a mucus gel that covers the luminal surface of the OE (Harkema et al. 2006). This mucus of the OE is believed to play a major role in detecting and discriminating between odors because it bathes the cilia of the olfactory receptor neurons, odorant receptors, olfactory xenobioticmetabolizing enzymes, and bacteria that are essential for odor perception (Heydel et al. 2013; François et al. 2016). The exact composition of GFMs in BGs is not known. Mucin production in humans is usually assessed by cell and explant culture from the RE, because the OE is not easily accessible. In contrast, the mouse may be a good model for GFM studies, but immunohistochemical data must be interpreted with caution because of the size and complexity of the mucin peptide and the high number of sugar chains that decorate the mucin backbone.

We recently recorded specific fluorescent activity by confocal laser endomicroscopy in the nose of a green fluorescent protein (GFP)-reporter Muc5b mouse, engineered by homologous recombination (Portal et al. 2017b), but the specific localization of both Muc5ac and Muc5b is not clear. Here we used immunohistochemistry to find that Muc5ac is expressed by the goblet cells of 
the RE, whereas BGs in the OE likely secrete Muc5b exclusively. Profile expression specificity of Muc5b was confirmed using wild-type (WT) and Muc5b genetically-deficient (Muc5b ${ }^{-/}$) mice. Last, using lectin staining, we observed that the terminal glycotopes of GFMs of the RE are fucosylated while those of Muc5b are sialylated.

\section{Materials and methods}

\section{Mice}

Floxed Muc5b-GFP reporter mice (Muc5b ${ }^{\mathrm{f} / \mathrm{f}}$ ) with a C57BL/6 genetic background (Desseyn et al. 2018) were bred in collaboration with Genoway (Lyon, France) with a C57BL/6 Cre recombinaseexpressing deleter mouse strain (Chen et al. 2015) to excise the last two exons of $M u c 5 b$ encompassing the single AATAAA signal, the single 3' untranslated region (UTR), and the GFP sequence. WT and GFP alleles were determined by polymerase chain reaction (PCR) using two oligonucleotides (P1 and P2) and PCR cycles as previously described (Portal et al. 2017b). The knockout allele was determined using the same conditions but a third (antisense) oligonucleotide (P3) was added in the reaction mix: 5'-GCAGTCCAGCCAGGACATTATCAGC-3' (Fig. 1a, b). Mice were housed in a specific pathogen-free animal facility and received standard chow diet ad libitum. A total of 14 mice with different genotypes (WT, Muc5b-GFP, and Muc $5 b^{-/}$), aged between 8 and 12 weeks, were used in this study. Animal protocols were in accordance with the French Guide for the Care and Use of Laboratory Animals and with the guidelines of the European Union.

\section{Histology and immunohistochemistry}

Mice were sacrificed by lethal anesthesia and their noses were harvested immediately. The nasal cavity was removed by one cut along the orbital bone between the eyes and one cut in the distal hard palate at the level of the first molar teeth. Excess soft tissue was removed, and the nose was rinsed in phosphate-buffered saline (Gibco BRL, France), decalcified in 10\% EDTA for at least two 
weeks, and then embedded in paraffin. Three locations in the nasal cavity were chosen: a proximal section (T1) taken immediately posterior to the upper incisor, an intermediate section taken at the level of the incisive papilla (T2), and a distal section (T3) taken at the level of the second palate ridge containing mainly OE (Fig. 1c). For each location serial five-micron-thick sections were prepared. Histological staining was performed as described before using Alcian Blue-periodic acid Schiff (AB-PAS) coloration (Gouyer et al. 2010). For immunohistochemistry, primary polyclonal anti-Muc5b (CP1), monoclonal anti-MUC5AC (45M1, kindly given by J. Bara), and commercial rabbit polyclonal anti-GFP antibodies (ab290; Abcam, Cambridge, UK), which has been used successfully by hundreds of researchers antibodies, were used (Lidell et al. 2008; Gouyer et al. 2010; Valque et al. 2011; Portal et al. 2017b, a). Fluorescein isothiocyanate (FITC)-conjugated secondary antibodies (Jackson ImmunoResearch Laboratories, West Grove, PA) were used to detect the primary antibodies. Because Muc5ac immunostaining requires a citrate pretreatment, dual Muc5b and Muc5ac immunostaining was performed only on Muc5b-GFP reporter and Muc5b $\mathrm{b}^{-/}$ mice using the anti-GFP antibody. FITC-conjugated anti-rabbit and tetramethylrhodamine (TRITC) anti-mouse secondary antibodies were used. TRITC-conjugated Maackia amurensis agglutinin (MAA) and TRITC-conjugated Ulex europaeus agglutinin I (UEA-1) lectins (EY Laboratories, San Mateo, CA, USA), which recognize mucin terminal glycotopes $\alpha-(2,3)$-linked sialic acid and fucose $\alpha-(1,2)$-galactose, respectively, were used as described previously (Gouyer et al. 2015). Dual labeling using MAA and UEA-1 lectins was performed with TRITC-conjugated MAA and fluorescein isothiocyanate (FITC)-conjugated UEA-1 lectins. Nuclei (blue) were counterstained with Hoechst 33258 as before (Valque et al. 2011). Three to five noses from each genotype were analyzed. High quality captures in bright field and fluorescence were performed, and images were digitized on an Axio Scan (Carl Zeiss, Oberkochen, Germany). Z1 scanner and processed with ZEN software (Carl Zeiss). 


\section{Results and discussion}

\section{Mucin expression in the nasal airway}

Muc5b production has been reported recently in mouse BGs in one study using immunohistochemistry (Chen et al. 2018), but Chen et al. noted that they could not get the currently available antibodies that are specific for mouse Muc5ac to work in decalcified specimens. Another group reported that rat and mouse BGs might produce Muc5b, but secrete mainly Muc5ac (Solbu and Holen 2012). In this last work, Muc5ac staining was observed using a mouse monoclonal antibody (Clone SPM488). However, this antibody has not been validated in mouse and is directed against a nonglycosylated synthetic 20 -mer peptide from the tandem repeat sequence of the human mucin MUC5AC (Reis et al. 2000) that is not conserved in the mouse Muc5ac sequence. In the present study, we took advantage of our reporter Muc5b-GFP mouse to determine the expression pattern of Muc5b using two antibodies, one directed against a "naked" mucin peptide (Valque et al. 2011), and the other against the GFP-tag of the reporter Muc5b transgenic mouse. Additionally, we studied the expression of the other major respiratory GFM, Muc5ac (Valque et al. 2011). Transverse sections from the proximal (T1) region, which predominantly contains RE, to the distal (T3) nasal airway (Fig. 1c), which predominantly contains OE, were analyzed by AB-PAS staining and immunohistochemistry. In the proximal nasal airway (T1), AB-PAS staining showed glycoconjugates in BGs underlying the OE and in mucous cells of the RE (Fig. 2). In the OE, BGs produced Muc5b but not Muc5ac as shown using the anti-GFP antibody in Muc5b-GFP mice (Fig. 2). This was confirmed using the anti-Muc5b antibody in WT mice (Suppl. Fig. 1) and in Muc5bGFP reporter mice (data not shown), whereas Muc5ac but not Muc5b was found exclusively in the RE of T1 sections of Muc5b-GFP reporter mice (Fig. 2) and WT mice (Suppl. Fig. 2). In the distal nasal airway (T3 sections), Muc5b but not Muc5ac is produced in the OE of reporter Muc5b-GFP mice (Fig. 3). This was further confirmed using the anti-Muc5b antibody in WT (Suppl. Fig. 2) and Muc5b-GFP reporter mice (data not shown). In contrast to T1, the RE was characterized by the 
expression of both Muc5b and Muc5ac in Muc5b-GFP reporter (Fig. 3) and WT mice (Suppl. Fig. 2).

\section{BGs are depleted in Muc5b-deficient mice}

To demonstrate that genetically removing the last two exons of the floxed reporter Muc $5 \mathrm{~b}$ mouse (Desseyn et al. 2018) leads to a Muc5b-deficient mouse (Fig. 1a) and to examine whether Muc5b invalidation leads to a compensatory production of Muc5ac, Muc5b-GFP homozygous mice after

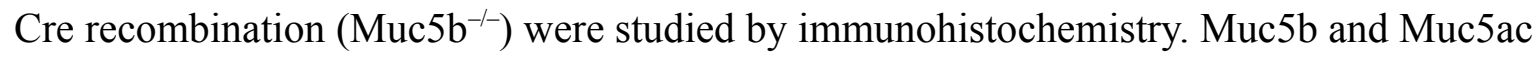
expression was analyzed in transverse sections of the distal airway (T3). In Muc $5 \mathrm{~b}^{-/-}$mice, AB-PAS staining showed a depletion of BGs that appeared nearly empty of glycoconjugates (Fig. 4). This was in agreement with the absence of staining using the anti-GFP antibody in the OE (Fig. 4) and the anti-Muc5b antibodies in Muc5b $b^{-/}$mice (Suppl. Fig. 3a). No difference in Muc5ac expression in the RE was observed in Muc5b $b^{-/-}$mice in comparison with Muc5b-GFP mice (see Figs 3 and 4), and

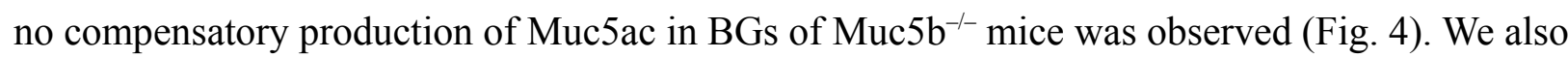
looked at Muc6 and Muc2 by immunohistochemistry using our home made antibody against mouse Muc6 (Gouyer et al. 2010) and the H300 anti-Muc2 antibody (SantaCruz, (Gouyer et al. 2011)). No Muc6 or Muc2 signal was observed in T1 and T3 sections from Muc5b-GFP and Muc5b $b^{-/-}$mice (data not shown).

\section{Muc5b and Muc5ac-specific lectin recognition in the nasal epithelium}

Immunofluorescence of pig MUC5B and MUC5AC in the lung showed that some lectins preferentially labeled either MUC5B or MUC5AC (Ermund et al. 2017; Ostedgaard et al. 2017). In the horse, the UEA-1 fucose lectin was found to label BGs in the OE (Lee et al. 2016). In the nose of mice, sialomucin with different terminal carbohydrate structures has been observed in the RE and OE, which may reflect differences in the susceptibility to bacterial colonization between the two epithelia (Ueno et al. 1994; Yoon et al. 1998). These two last studies reported that the mouse OE, but not the goblet cells of the RE is sialylated, whereas one study showed that mouse BGs produced 
sulfated but not sialylated glycoconjugates using high-iron diamine-AB staining (Kondo et al. 2009). To determine if there are specific lectins for nasal Muc5ac and Muc5b mucins, we used dual labeling with the two fluorescent-conjugated MAA and UEA-1 lectins that disclosed distinct goblet cell subpopulations in the mouse intestine (Gouyer et al. 2011). In T2 sections of Muc5b-GFP reporter and WT mice, Muc5b antibody staining colocalized with MAA in BGs and BG ducts (Fig. 5). Muc5ac seemed to colocalize with UEA-1 (Fig. 5) whereas MAA staining almost disappeared, and UEA-1 did not stain the OE of Muc $5 b^{-/-}$mice (Suppl. Fig. 3a). Furthermore, MAA did not label the RE (Suppl. Fig. 3a). In both Muc5b-GFP reporter and WT mice, double-labeling with fluorescent-conjugated MAA and UEA-1 lectins showed that MAA but not UEA-1 bound to BGs in the OE, whereas UEA but not MAA labeled mucous cells of the RE (Suppl. Fig. 3b). The preferential binding of MAA to Muc5b and UEA-1 to Muc5ac in the nasal airway indicates that the two main airway GFMs harbor distinct terminal glycotopes. Our observations are in agreement with results obtained in pig and rat airways. It has been shown that UEA-1 lectin and anti-MUC5AC antibodies stained the surface goblet cells in the lung of pigs (Ermund et al. 2017) and that wheat germ agglutinin lectin, which binds to N-acetyl-D-glucosamine and sialic acid, preferentially labeled MUC5B (Ostedgaard et al. 2017). In adult rat airway epithelium, fucosylated glycoconjugates were detected by UEA-1 in goblet cells (Castells et al. 1991). How important the differential $O$-glycosylation of the two mucins is remains to be elucidated. It might reflect distinct mucus architecture and properties between the the RE and the $\mathrm{OE}$, and specific microbiome in the two epithelia. Future investigations will need to clarify whether the microbiome differs between the two sites and in the absence of Muc5b.

In conclusion, we report here using WT, Muc5b-GFP reporter, and Muc5b-deficient mice that the expression of the two main respiratory mucins at the peptide level differs in specific regions in the upper airway. Muc5ac is produced only in the RE and is preferentially fucosylated, whereas Muc $5 \mathrm{~b}$ is produced by BGs in the OE and is preferentially sialylated. 
Ethical approval: All applicable international, national, and/or institutional guidelines for the care and use of animals were followed. This article does not contain any studies with human participants performed by any of the authors.

\section{Acknowledgments}

We thank J. Bara for the gift of the 45M1 antibody, M.H. Gevaert (Service Commun-Morphologie Cellulaire, Université de Lille) for the slides, J. Devassine and Y. Lepage from the EOPS animal facility (Université de Lille) for mouse colony management and S. Plet and M. Magnien (LIRIC) for genotyping and dissection and the Bio-imaging Center (plate-forme de microscopie photonique, Université Lille) for Carl Zeiss Axio Scan. Z1 scanner.

\section{Conflict of Interest}

The authors declare that they have no conflict of interest.

\section{References}

Ali MS, Pearson JP (2007) Upper airway mucin gene expression: a review. Laryngoscope 117:932938

Aust MR, Madsen CS, Jennings A, et al (1997) Mucin mRNA expression in normal and vasomotor inferior turbinates. Am. J. Rhinol. 11:293-302

Castells MT, Ballesta J, Madrid JF, et al (1991) Characterization of glycoconjugates in developing rat respiratory system by means of conventional and lectin histochemistry. Histochemistry 95:419-26

Chen CR, Kachramanoglou C, Li D, et al (2014) Anatomy and cellular constituents of the human olfactory mucosa: a review. J Neurol Surg B Skull Base 75:293-300. doi: 10.1055/s-00331361837

Chen G, Volmer AS, Wilkinson KJ, et al (2018) Role of Spdef in the Regulation of Muc5b Expression in the Airways of Naive and Mucoobstructed Mice. Am J Respir Cell Mol Biol 59:383-396. doi: 10.1165/rcmb.2017-0127OC 
Chen J, Kaiyala KJ, Lam J, et al (2015) In vivo structure-function studies of human hepatic lipase: the catalytic function rescues the lean phenotype of HL-deficient (hl-/-) mice. Physiol Rep 3:e12365. doi: 10.14814/phy2.12365

Corfield A (2017) Eukaryotic protein glycosylation: a primer for histochemists and cell biologists. Histochem Cell Biol 147:119-147. doi: 10.1007/s00418-016-1526-4

Desseyn J-L, Portal C, Gottrand F, Gouyer V (2018) Transgenic Mouse Reporter to Study Muc5b In Vivo. Ann Am Thorac Soc 15:S149-S153. doi: 10.1513/AnnalsATS.201802-085AW

Ermund A, Meiss LN, Rodriguez-Pineiro AM, et al (2017) The normal trachea is cleaned by MUC5B mucin bundles from the submucosal glands coated with the MUC5AC mucin. Biochem Biophys Res Commun 492:331-337. doi: 10.1016/j.bbrc.2017.08.113

François A, Grebert D, Rhimi M, et al (2016) Olfactory epithelium changes in germfree mice. Sci Rep 6:24687. doi: 10.1038/srep24687

Gouyer V, Dubuquoy L, Robbe-Masselot C, et al (2015) Delivery of a mucin domain enriched in cysteine residues strengthens the intestinal mucous barrier. Sci Rep 5:9577. doi: 10.1038/srep09577

Gouyer V, Gottrand F, Desseyn J-L (2011) The extraordinarily complex but highly structured organization of intestinal mucus-gel unveiled in multicolor images. PLoS One 6:e18761. doi: 10.1371/journal.pone.0018761

Gouyer V, Leir S-H, Tetaert D, et al (2010) The characterization of the first anti-mouse Muc6 antibody shows an increased expression of the mucin in pancreatic tissue of Cftr-knockout mice. Histochem Cell Biol 133:517-525. doi: 10.1007/s00418-010-0688-8

Gross EA, Swenberg JA, Fields S, Popp JA (1982) Comparative morphometry of the nasal cavity in rats and mice. $\mathrm{J}$ Anat 135:83-8

Harkema JR, Carey SA, Wagner JG (2006) The nose revisited: a brief review of the comparative structure, function, and toxicologic pathology of the nasal epithelium. Toxicol Pathol 34:25269. doi: $10.1080 / 01926230600713475$

Heydel J-M, Coelho A, Thiebaud N, et al (2013) Odorant-binding proteins and xenobiotic metabolizing enzymes: implications in olfactory perireceptor events. Anat Rec 296:1333-45. doi: 10.1002/ar.22735

Kondo K, Watanabe K, Sakamoto T, et al (2009) Distribution and severity of spontaneous lesions in the neuroepithelium and Bowman's glands in mouse olfactory mucosa: age-related progression. Cell Tissue Res 335:489-503. doi: 10.1007/s00441-008-0739-9

Lee K-H, Park C, Bang H, et al (2016) Histochemical study of the olfactory mucosae of the horse. Acta Histochem 118:361-8. doi: 10.1016/j.acthis.2016.03.006

Lidell ME, Bara J, Hansson GC (2008) Mapping of the 45M1 epitope to the C-terminal cysteinerich part of the human MUC5AC mucin. FEBS J 275:481-9. doi: 10.1111/j.17424658.2007.06215.x 
Linden SK, Sutton P, Karlsson NG, et al (2008) Mucins in the mucosal barrier to infection. Mucosal Immunol 1:183-197

Ostedgaard LS, Moninger TO, McMenimen JD, et al (2017) Gel-forming mucins form distinct morphologic structures in airways. Proc Natl Acad Sci U S A 114:6842-6847. doi: $10.1073 /$ pnas. 1703228114

Paulsen F (2006) Cell and molecular biology of human lacrimal gland and nasolacrimal duct mucins. Int Rev Cytol 249:229-79. doi: 10.1016/S0074-7696(06)49005-7

Portal C, Gouyer V, Gottrand F, Desseyn J-L (2017a) Preclinical mouse model to monitor live Muc5b-producing conjunctival goblet cell density under pharmacological treatments. PLoS One 12:e0174764. doi: 10.1371/journal.pone.0174764

Portal C, Gouyer V, Magnien M, et al (2017b) In vivo imaging of the Muc5b gel-forming mucin. Sci Rep 7:44591. doi: 10.1038/srep44591

Radicioni G, Cao R, Carpenter J, et al (2016) The innate immune properties of airway mucosal surfaces are regulated by dynamic interactions between mucins and interacting proteins: the mucin interactome. Mucosal Immunol 9:1442-1454. doi: 10.1038/mi.2016.27

Reis CA, David L, Carvalho F, et al (2000) Immunohistochemical Study of the Expression of MUC6 Mucin and Co-expression of Other Secreted Mucins (MUC5AC and MUC2) in Human Gastric Carcinomas. J Histochem Cytochem 48:377-388. doi: 10.1177/002215540004800307

Solbu TT, Holen T (2012) Aquaporin pathways and mucin secretion of Bowman's glands might protect the olfactory mucosa. Chem Senses 37:35-46. doi: 10.1093/chemse/bjr063

Ueno K, Hanamure Y, Ohyama M (1994) Differences in terminal carbohydrate structures of sialomucin in the murine nasal cavity. Eur Arch Otorhinolaryngol 251:119-22

Valque H, Gouyer V, Husson M-O, et al (2011) Abnormal expression of Muc5b in Cftr-null mice and in mammary tumors of MMTV-ras mice. Histochem Cell Biol 136:699-708. doi: 10.1007/ s00418-011-0872-5

Yoon JH, Kim KS, Kim SS, Lee JG (1998) Sialoglycoproteins and penultimate sugar expression pattern in developing murine olfactory and respiratory mucosa. Yonsei Med J 39:20-6. doi: 10.3349/ymj.1998.39.1.20 
a
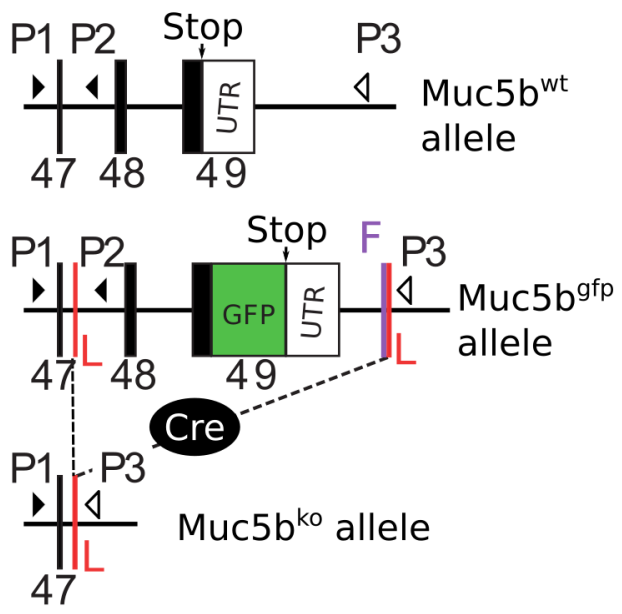

b

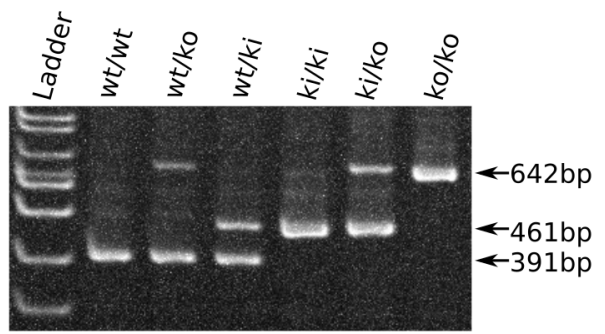

C

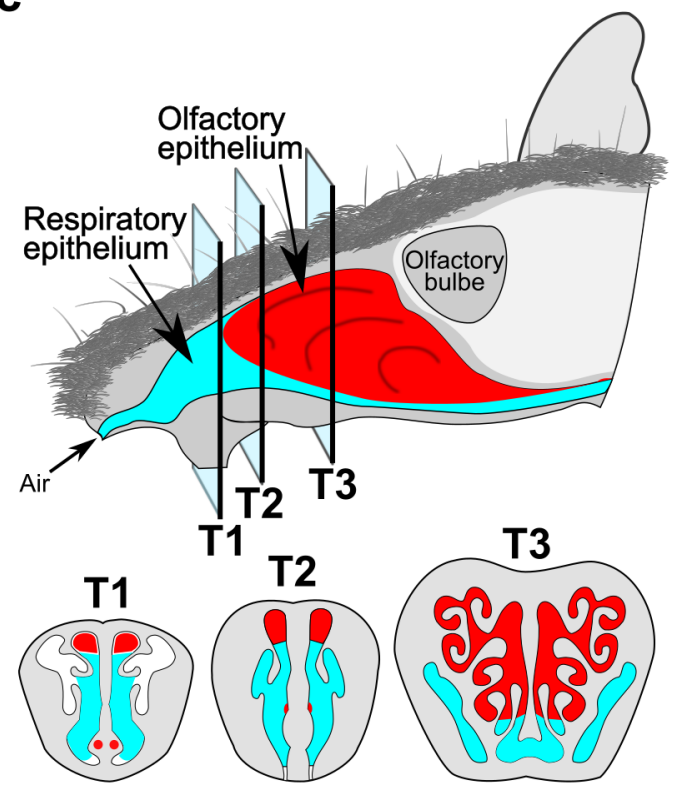

Fig. 1. Muc $5 b^{-/-}$mouse line, genotyping, and schematic drawing of the epithelium of the mouse nose. a. Schematic representation of the $3^{\prime}$-end of the mouse Muc5b with its last three exons (4749) and its unique 3' UTR. The reporter Muc5b-GFP mouse was obtained by homologous recombination to insert a GFP sequence in-frame with Muc5b (Desseyn et al. 2018). The last two exons are flanked by $\operatorname{LoxP}(\mathrm{L})$ sites. A unique FRT (F) site remains after the excision of a neomycin cassette. The Muc5b-deficient knockout (ko) allele is obtained after Cre excision of the last two exons. The three oligonucleotides P1-3 and their orientation used for genotyping are indicated by triangles. b. Example of genotyping obtained by PCR analyzed in $8 \%$ acrylamide gel using DNA samples from all mouse genotypes with predicted bands of 391,461 , and $642 \mathrm{bp}$ for the WT $\left(\mathrm{Muc5b}^{+}\right.$), the Muc5b-GFP knock-in (ki), and the Muc5b-deficient (ko) alleles, respectively. c. Schematic representation of the mouse nose adapted from Harkema et al. (Harkema et al. 2006) showing transversal sections T1-3 used in the study with the RE in blue and the OE in red. 


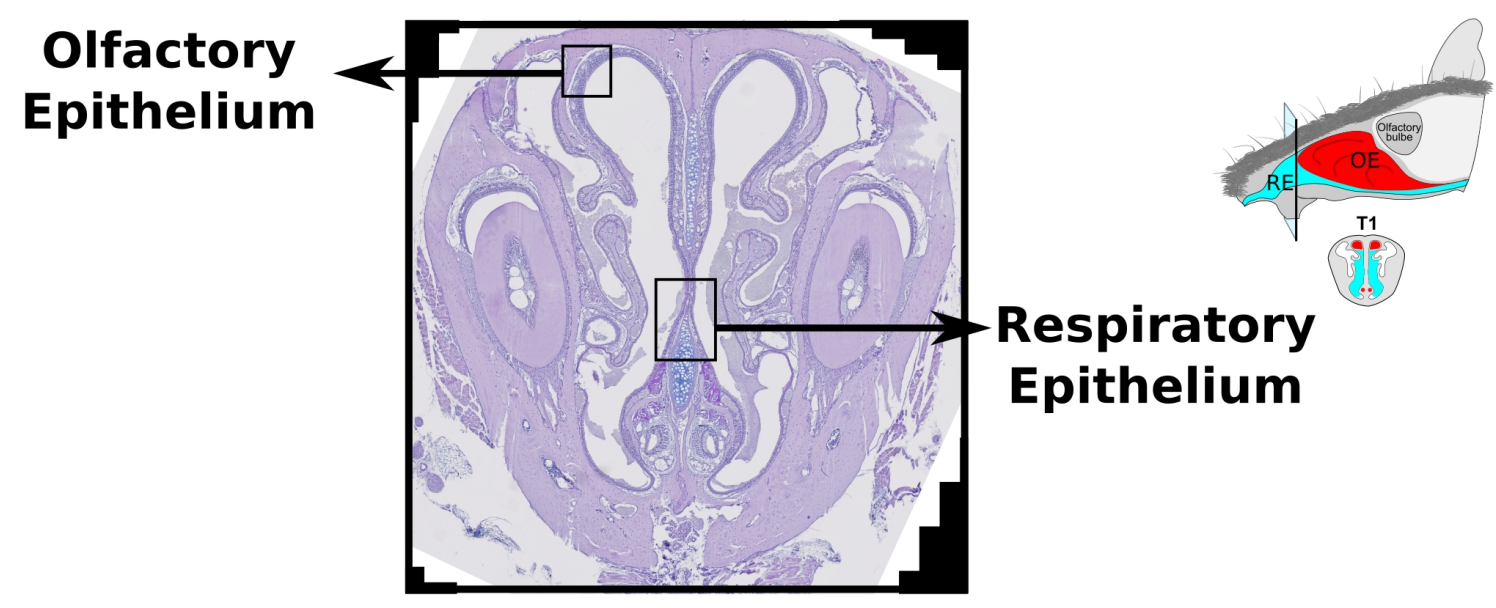

Olfactory Epithelium

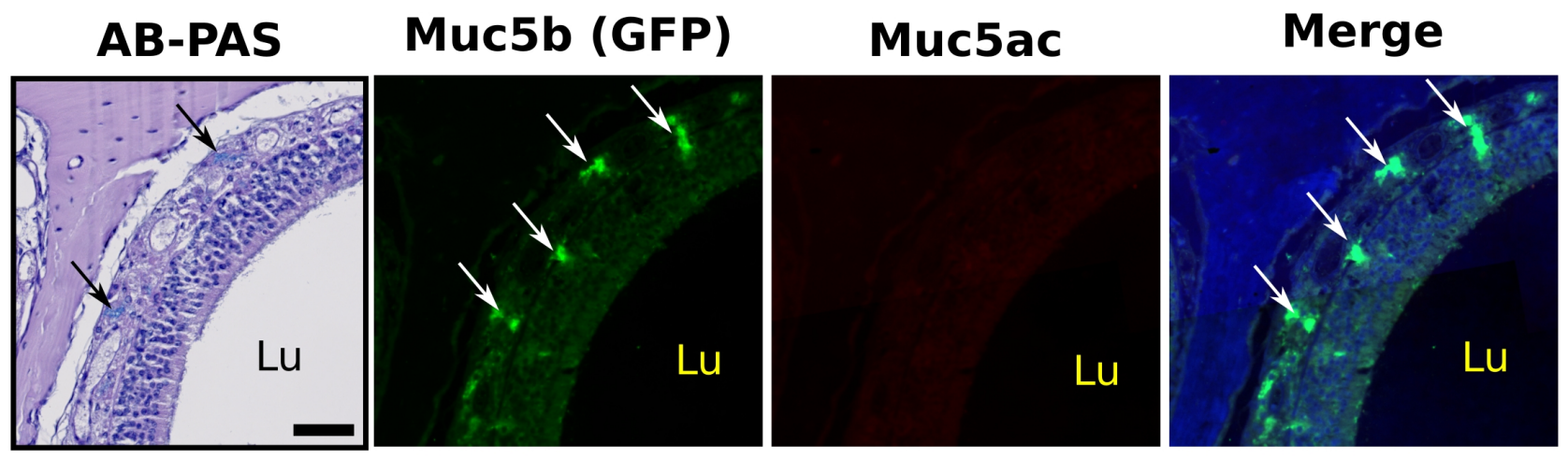

Respiratory Epithelium

AB-PAS Muc5b (GFP) Muc5ac
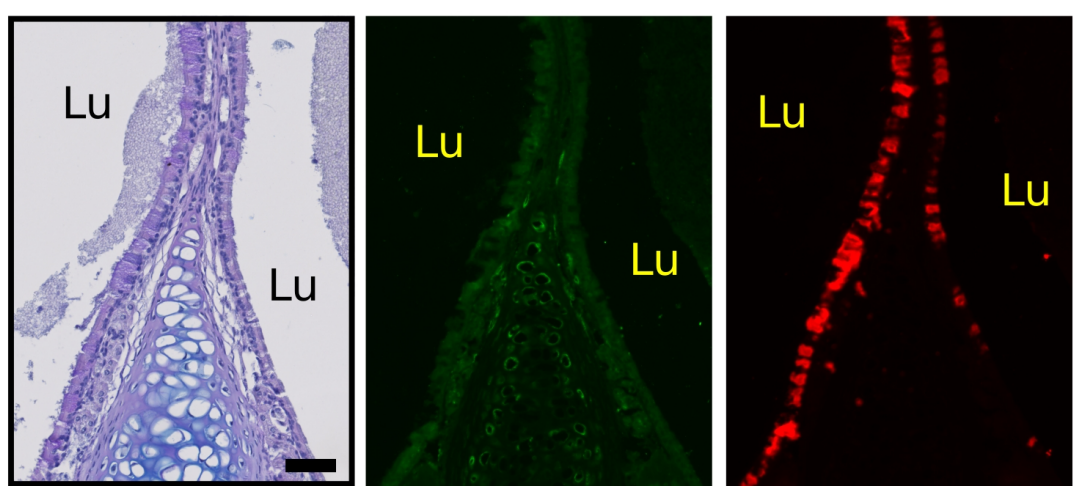

Merge

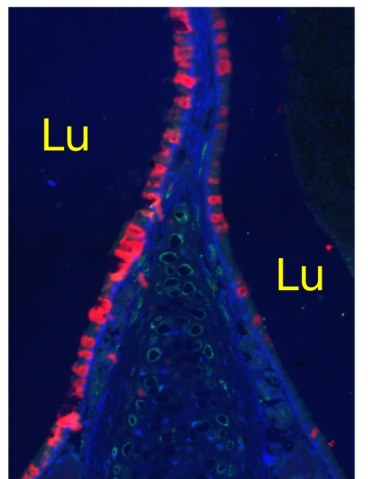

Fig. 2. Immunohistochemical analysis of GFP and Muc5ac in nose coronal sections of the proximal (T1) nasal airway of Muc5b-GFP reporter mice. Serial sections were stained with AB-PAS and antibodies against GFP (green) and Muc5ac (red). Higher magnification images taken from the boxed areas in the $\mathrm{OE}$ and $\mathrm{RE}$ are shown. BGs (arrow) are filled with glycoconjugated materials that are AB-PAS-positive and specifically recognized by the anti-GFP antibody, but not the antiMuc5ac antibody. Mucous cells of the RE expressed Muc5ac, but not Muc5b. Lu: lumen. Scale bar $=50 \mu \mathrm{m}$. 


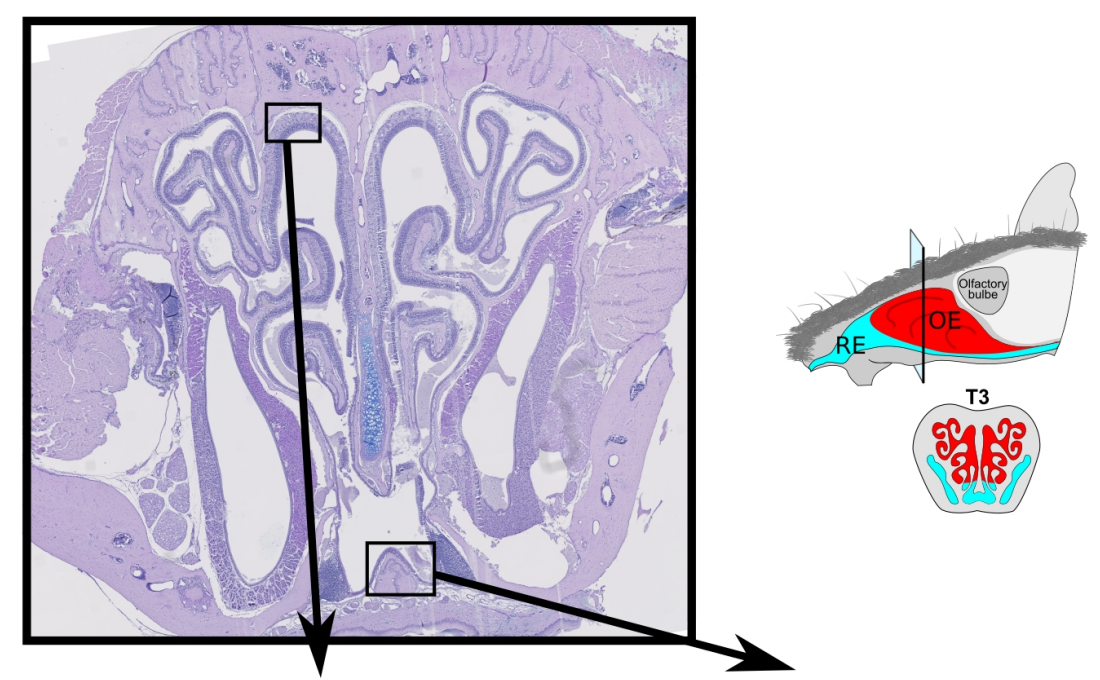

Olfactory Epithelium
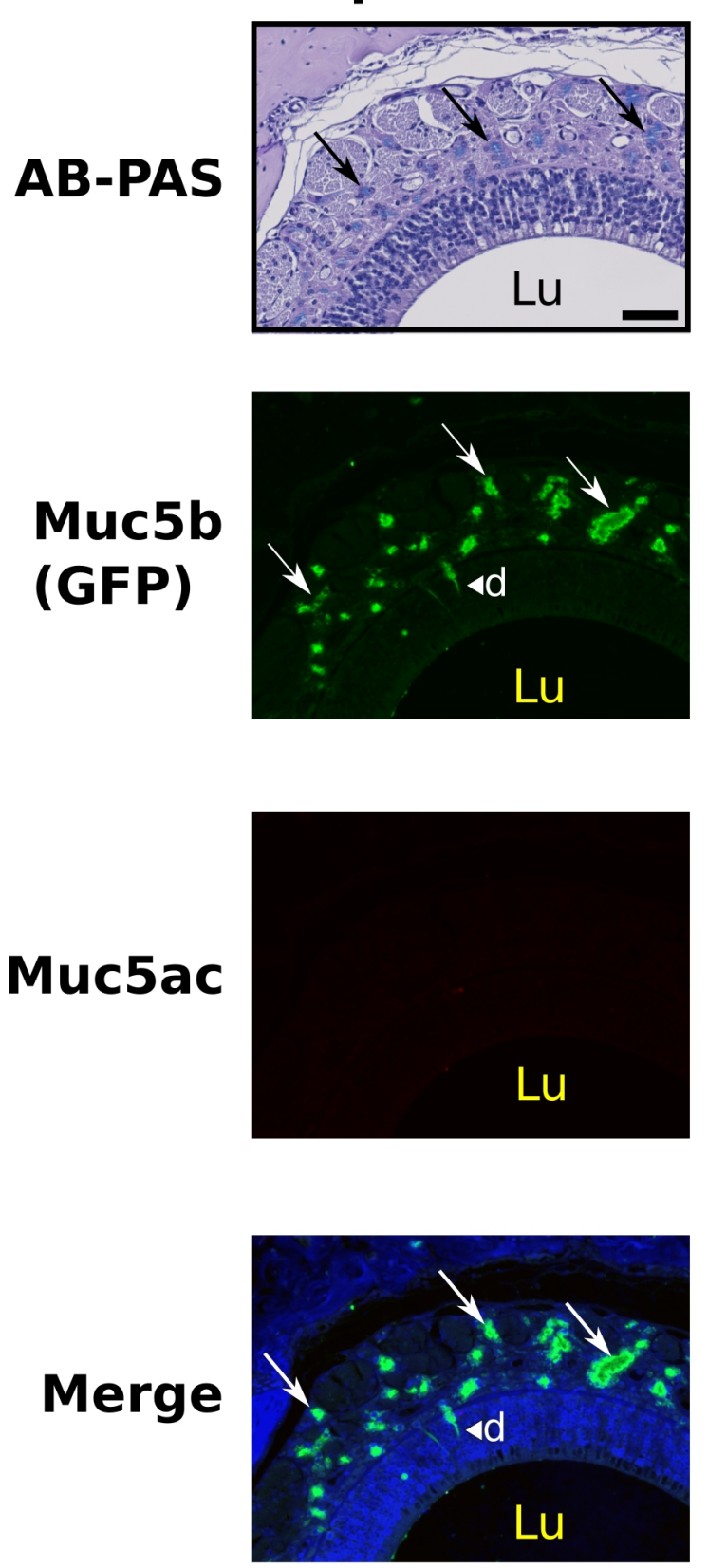

Respiratory Epithelium
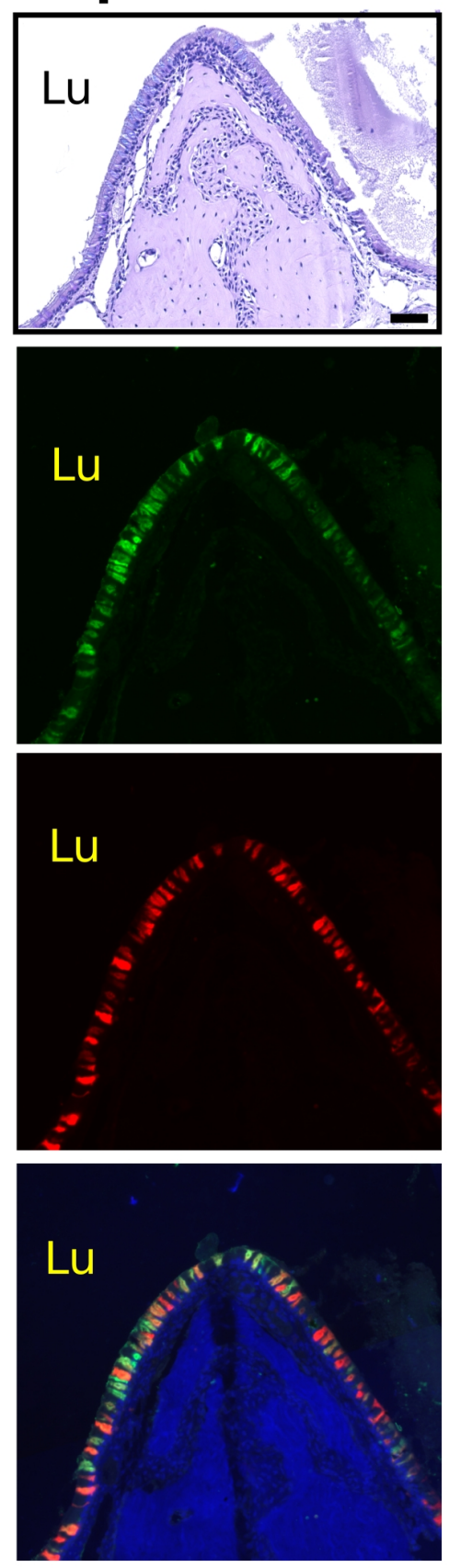

Fig. 3.

Immunohistochemical analysis of GFP and Muc5ac in nose coronal sections of the distal (T3) nasal airway of Muc5b-GFP mice. Serial sections were stained with AB-PAS and antibodies against GFP (green) and Muc5ac (red). Higher magnification images taken from the boxed areas in the OE and RE are shown. BGs (arrow) in the $\mathrm{OE}$ are filled with glycoconjugated materials that are ABPAS-positive and specifically recognized by the anti-GFP antibody. GFP-positive ducts (d) are also observed. Mucous cells in the RE expressed Muc5ac, Muc5b, or both. Lu: lumen. Scale bar $=50 \mu \mathrm{m}$. 


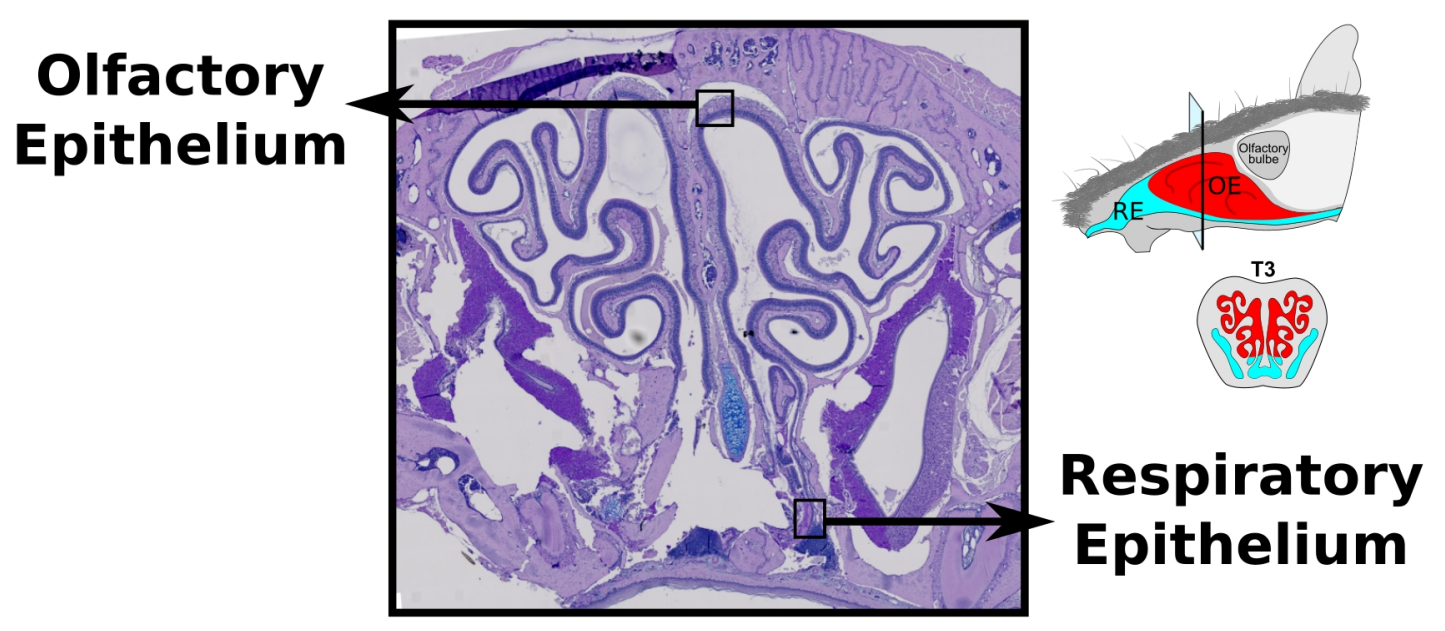

Olfactory Epithelium

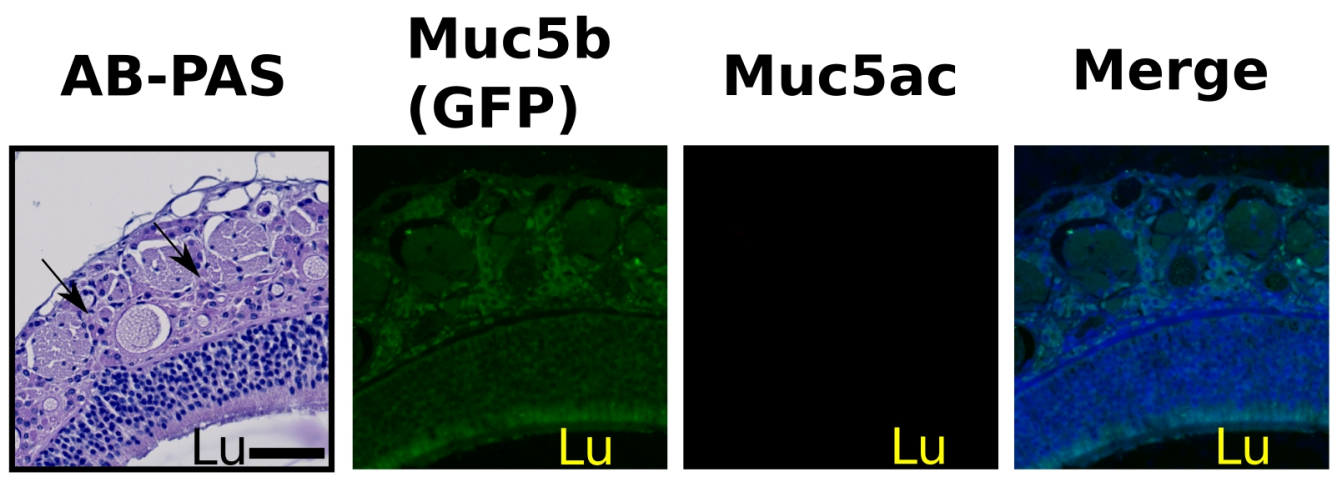

Respiratory Epithelium

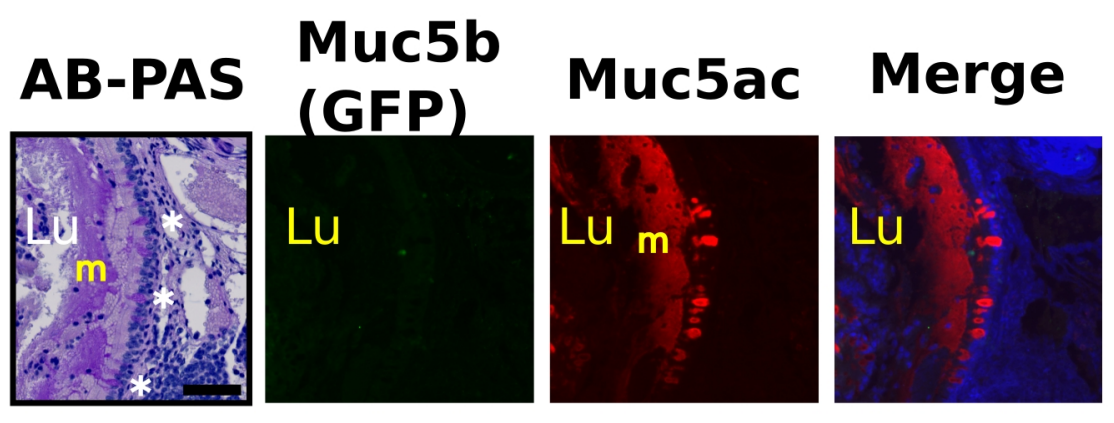

Fig. 4. Immunohistochemical analysis of GFP and Muc5ac in nose coronal sections of the proximal (T3) nasal airway from Muc5b $\mathrm{b}^{-/}$mice. Serial sections were stained with AB-PAS and antibodies against GFP (green) and Muc5ac (red). Higher magnification images taken from the boxed areas in the $\mathrm{OE}$ and RE are shown. BGs (arrow) in the OE are depleted as almost no glycoconjugates and no GFP-staining was observed. Mucous cells in the RE expressed Muc5ac, but not Muc5b. Lu: lumen. Scale bar $=50 \mu \mathrm{m}$. 


\section{Olfactory Epithelium}
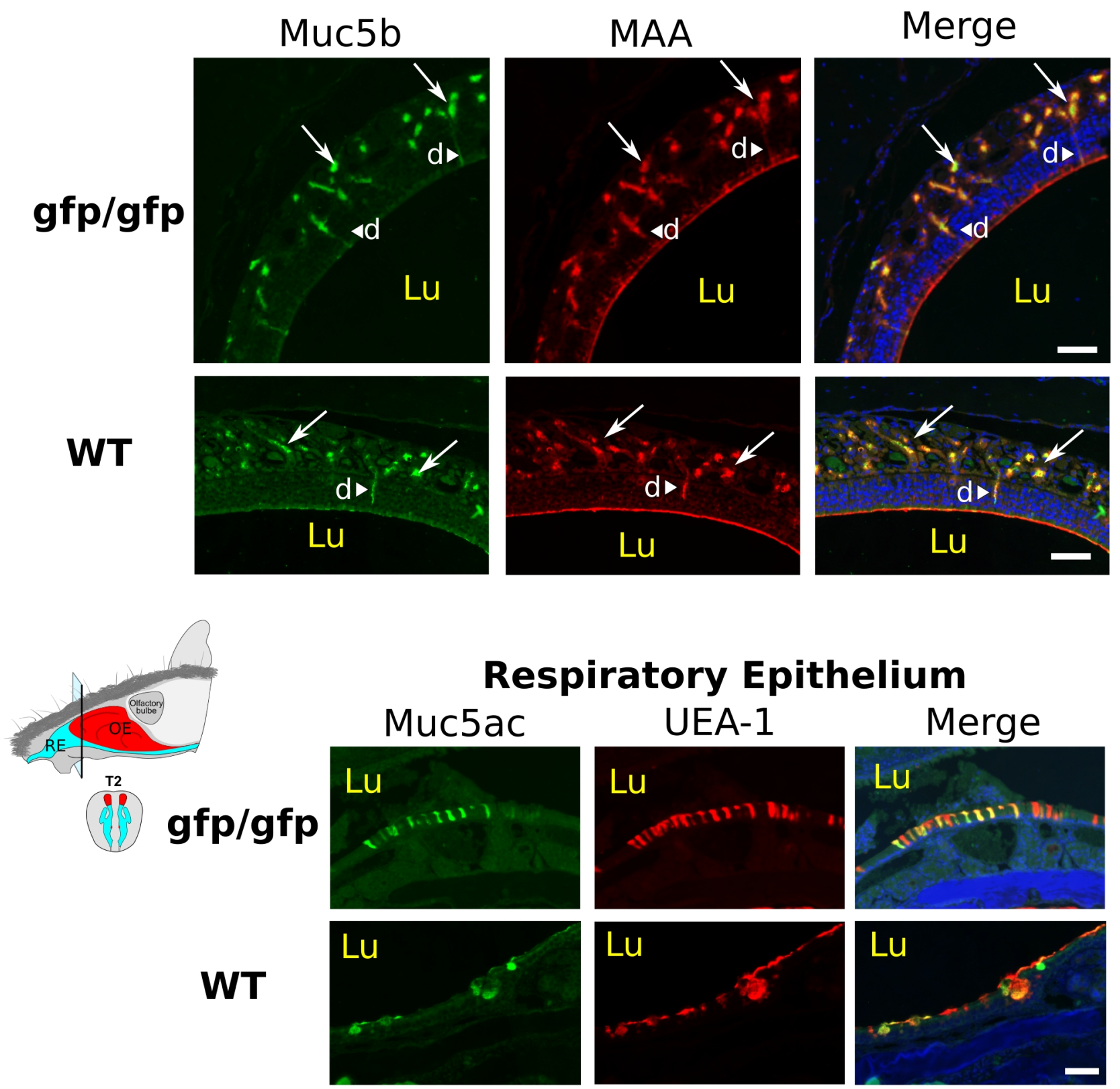

Fig. 5. Multilabel immunohistochemical analysis of Muc5b and Muc5ac lectins in the OE and RE of coronal sections of the T2 nasal airway from WT and Muc5b-GFP reporter mice. High magnification images of the $\mathrm{OE}$ and RE are shown. Colocalization of Muc5b and MAA lectin was observed in BGs (arrows) underlying the OE and in Bowman's gland ducts (d). Mucous cells of the $\mathrm{RE}$ are recognized by UEA lectin that colocalized in many cells with Muc5ac (yellow). Lu: lumen. Scale bar $=50 \mu \mathrm{m}$. 


\section{Supplementary material}
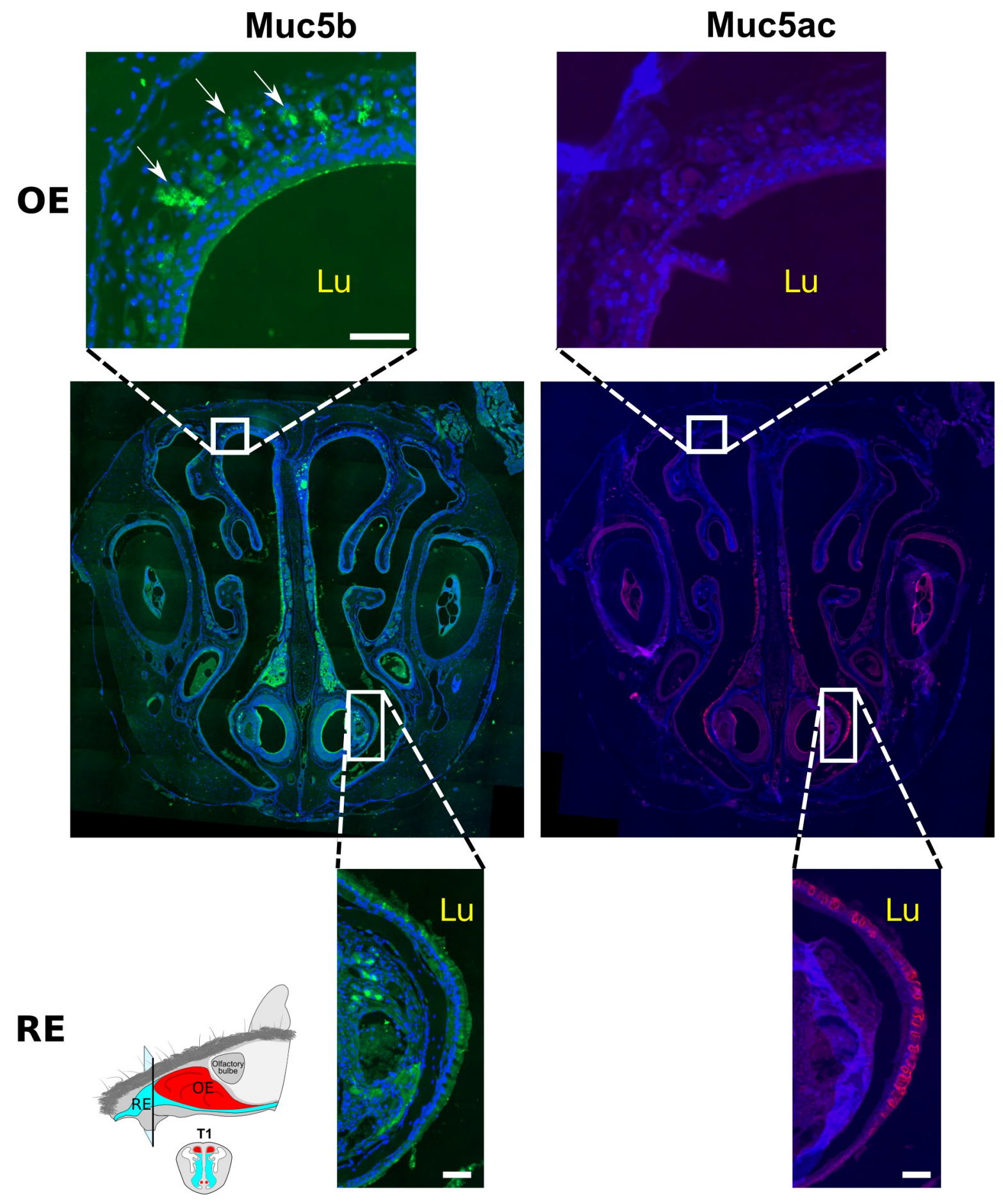

Suppl. Fig. 1 Immunohistochemical analysis of Muc5b and Muc5ac in nose coronal sections of the proximal (T1) nasal airway of WT mice. Serial sections were stained with antibodies against Muc5b (green) and Muc5ac (red). Higher magnification images taken from the boxed areas in the OE and RE are shown. Arrows indicate BGs. Lu: lumen. Scale bar $=50 \mu \mathrm{m}$. 


\section{Supplementary material}

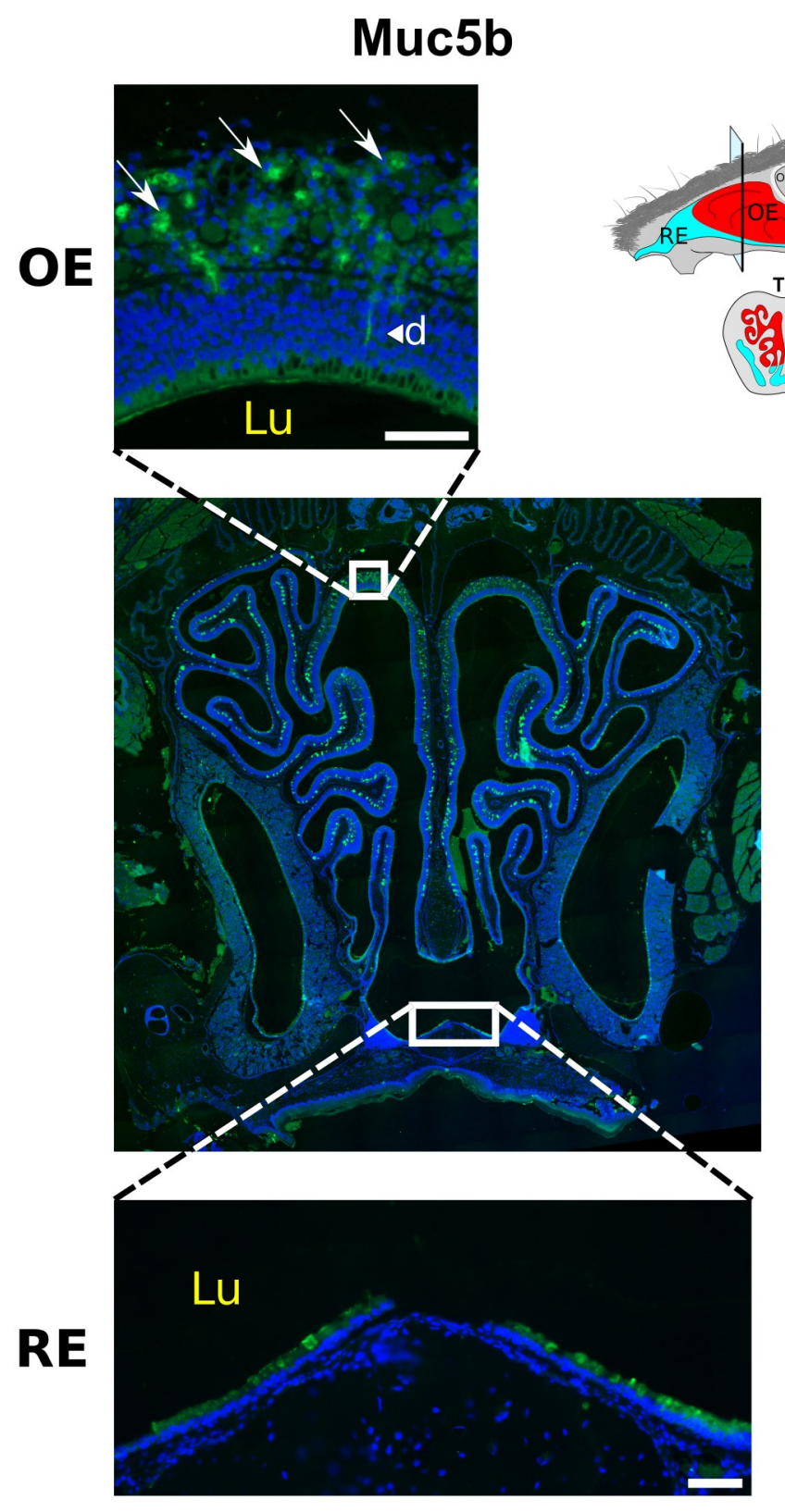

\section{Muc5ac}
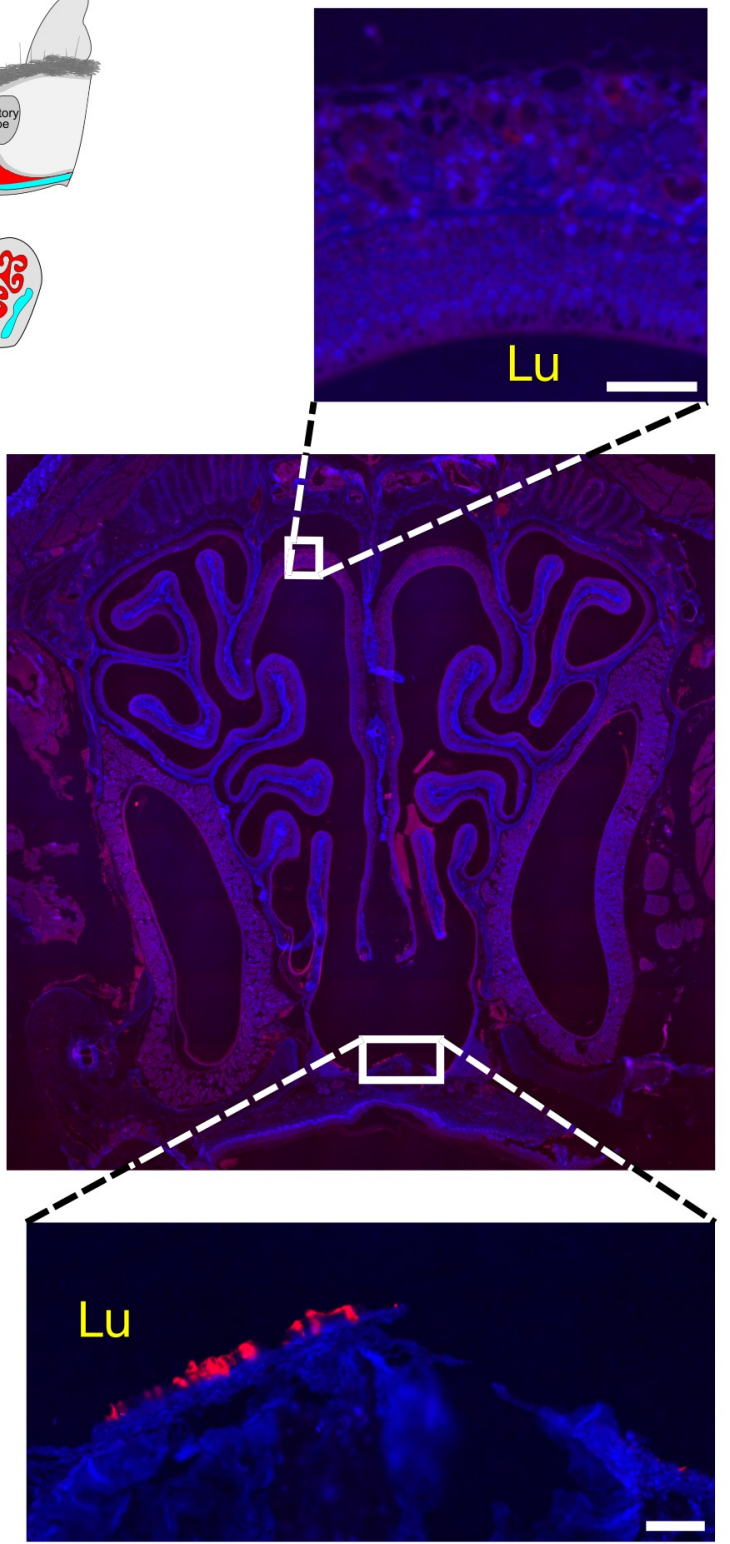

Suppl. Fig. 2 Immunohistochemical analysis of Muc5b and Muc5ac in nose coronal sections of the proximal (T3) nasal airway of WT mice. Serial sections were stained with antibodies against Muc5b and Muc5ac. Higher magnification images of the OE and RE are shown. Muc5b staining was observed in BGs (arrows) and BGs ducts in the OE. Goblet cells of the RE produced both Muc5b and Muc5ac, with a higher number of goblet cells producing Muc5ac. Lu: lumen. Scale bar $=50 \mu \mathrm{m}$. 


\section{Supplementary material}
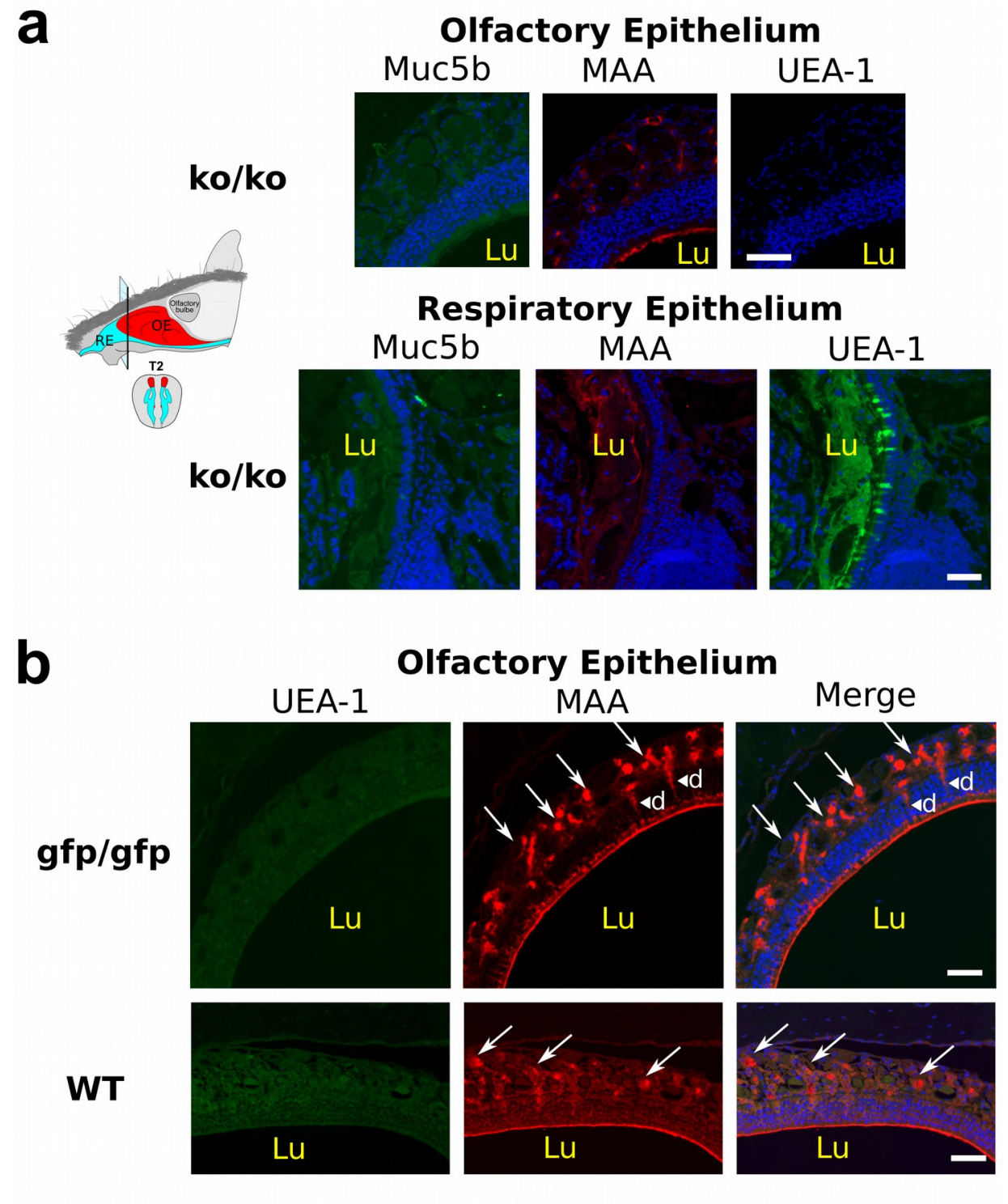

Olfactory Epithelium

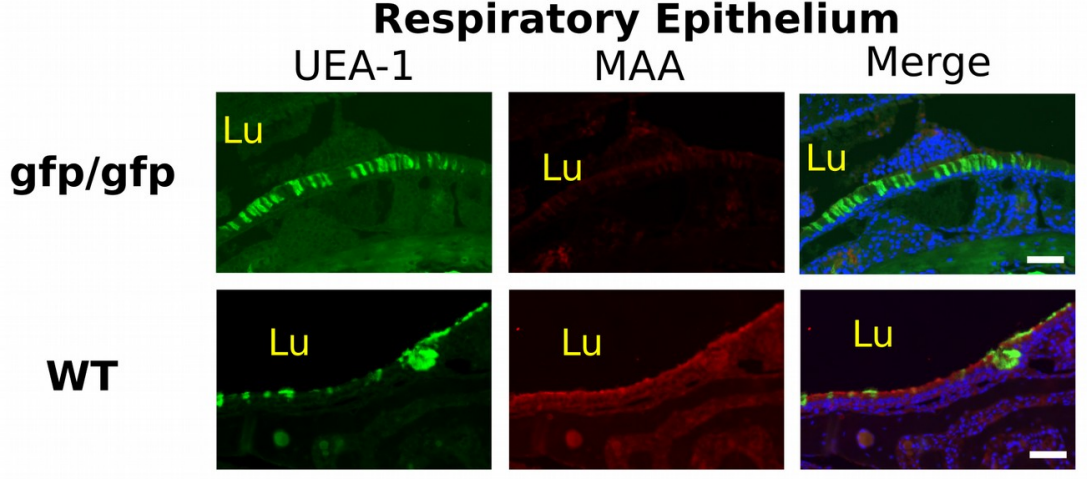

Suppl. Fig. 3 Multilabel immunohistochemical analysis of Muc5b with MAA or UEA-1 lectin in the OE and RE of coronal section T3 of the nasal airway from Muc5 $\mathrm{b}^{-/-}$mice and with MAA and UEA-1 lectins in the OE and RE of coronal section T2 of the nasal airway from Muc5b-GFP reporter and WT mice. a. BGs underlying the OE are not visible (depleted) and are not stained with either the Muc5b antibody or MAA. Mucous cells of the RE were stained by UEA-1 and very faintly by MAA. Lu: lumen. Scale bar $=50 \mu \mathrm{m}$. b. High magnification images of the OE and RE are shown. MAA lectin binding was observed in BGs (arrows) underlying the OE and in Bowman's gland ducts (d). Mucous cells of the RE are recognized by UEA-1 lectin. Lu: lumen. Scale bar $=50 \mu \mathrm{m}$. 